\title{
Early postnatal alteration of body composition in preterm and small-for-gestational-age infants: implications of catch-up fat
}

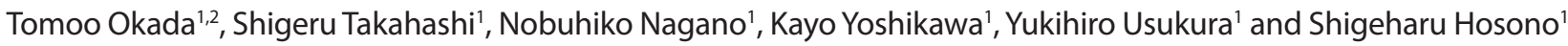

The concept of the developmental origins of health and disease is based on studies by Barker et al. They proposed a hypothesis that undernutrition in utero permanently changes the body's structure, function, and metabolism in ways that lead to atherosclerosis and insulin resistance in later life. In addition, profound effects on the extent of body fatness and insulin sensitivity are demonstrated, if there is a "mismatch" between prenatal and postnatal environments. In previous studies, undernutrition in utero has been evaluated simply by birth weight itself or birth weight for gestational age, and the degree of mismatch has been estimated by postnatal rapid weight gain. Recently, we investigated subcutaneous fat accumulation in small-for-gestational-age infants and found that a rapid catch-up in skinfold thickness developed prior to the body weight catch-up. Furthermore, insulin-like growth factorI and lipoprotein lipase mass concentrations also demonstrate rapid increase during the neonatal period with fat accumulation. Investigating the precise mechanisms of developmental origins of health and disease including mediating metabolic and hormonal factors may provide a new approach to prevent atherosclerosis and insulin resistance. Better management of undernutrition during gestation and neonatal growth during the early postnatal period is an important theme for future health.

\footnotetext{
$\mathbf{T}$
} he prevalence of obesity in children has been increasing worldwide, and consequently metabolic syndrome (MetS) is also becoming a serious health problem. A follow-up study has suggested that the MetS phenotype persists over time and tends to progress clinically even in children and adolescents (1). Therefore, the focus should be on the prevention and early detection of metabolic risks. Recent studies suggest that MetS may originate in utero. Barker et al. first proposed this concept (2). They found a geographic correlation in England and Wales, which suggested a positive relationship across locations between ischemic heart disease mortality rates in 1968-78 and infant mortality in 1921-25. Their subsequent studies demonstrated that infants with low birth weight (LBW) or born small for gestational age (SGA) are associated with increased rates of type 2 diabetes, hypertension, and coronary heart disease in adulthood $(3,4)$. Their epidemiological findings have been confirmed around the world. It is suggested that undernutrition in utero permanently changes the body's structure, function, and metabolism in ways that lead to atherosclerosis and insulin resistance in later life (5). SGA infants are usually defined as having a birth weight more than $2 \mathrm{SD}$ below the mean or less than the 10th percentile for the gestational age. Birth weight is a final result of intrauterine growth, and the fetal growth pattern of SGA infants is heterogeneous. However, apart from physiological variations in fetal growth, nutrient availability is a major determinant of birth weight. Furthermore, profound effects are demonstrated if a "mismatch" between prenatal and postnatal environments results in postnatal rapid growth $(6,7)$. Many studies have confirmed the relationship between MetS-associated features and catch-up growth of preterm or SGA infants (8). However, the precise mechanisms of postnatal rapid growth are poorly understood, including those that mediate metabolic and hormonal factors that might be linked to the development of MetS, type 2 diabetes, and cardiovascular diseases in later life. In this review, we summarize the data presented in the published literature regarding early postnatal changes in body composition, and discuss recent advances in the understanding of the mechanisms underlying postnatal rapid fat accumulation in preterm and SGA infants.

\section{MECHANISMS UNDERLYING THE DEVELOPMENTAL ORIGINS OF HEALTH AND DISEASE}

The central concept of developmental origins of health and disease is that the intrauterine and infantile environments induce developmental changes that have long-term effects on health and disease risks in later life. Some possible mechanisms have been proposed to explain the link between intrauterine undernutrition and metabolic risks (9).

\section{Hypothalamic-Pituitary-Adrenal (HPA) Axis Hypothesis}

Changes in the regulation of the HPA axis are believed to give rise to one mechanism that mediates the linkage (10-12). An animal model has suggested that periconceptional undernutrition markedly activates fetal HPA axis activity in late gestation, leading to preterm birth (13). Another model, rats in which LBW was induced by administering dexamethasone to 


\section{Body composition of preterm SGA infants}

the dam during the final $7 \mathrm{~d}$ of pregnancy, demonstrated liverspecific insulin resistance associated with increased morning plasma adrenocorticotropic hormone levels and elevated corticosterone secretion (14). These studies suggest that prenatal stress can result in chronic hyperactivity of the HPA axis, followed by increased plasma corticosterone levels and hepatic insulin resistance. However, the long-term impact of HPA axis activation is controversial. Periconceptional undernutrition of sheep is reported to have only a minor influence on HPA axis function in their young adult offspring (15). In addition, the HPA axis can be reset by postnatal influences (16). A metaanalysis of human epidemiological studies reported an inverse association between birth weight and circulating cortisol level, although the majority of studies were underpowered. Therefore, the strength of the overall association between birth weight and circulating cortisol level appears to be weak (11).

\section{Fetal Insulin Hypothesis}

Hattersley and Tooke proposed the fetal insulin hypothesis as an alternative explanation of the association of LBW with diabetes and vascular disease (17). They suggested that genetic factors are related to birth weight and to diabetes risk. Monogenic diseases that impair glucose sensing, lower insulin secretion, or increase insulin resistance support this hypothesis. An association was recently observed between a polymorphism of the angiotensinogen gene and LBW and elevated fetal total glycated hemoglobin at birth (18). Associations have also been demonstrated between polymorphisms of some other genes and birth weight $(19,20)$. Therefore, common genetic factors may predispose the association of LBW with insulin resistance.

\section{Catch-Up Hypothesis}

Another explanation of the linkage is the catch-up hypothesis. Previously, Eriksson et al. reported that the highest death rates from coronary heart disease occurred in men that were born with LBW or low ponderal index, but whose weight caught up so that they had an average or above average BMI at 11 $y$ of age, suggesting that catch-up growth during childhood modifies the increased risk of death from coronary heart disease in later life (21). Thereafter, many epidemiological studies have demonstrated that infants born preterm or SGA with catch-up growth had a higher risk not only for cardiovascular diseases, but also for developing obesity, hypertension, type 2 diabetes, and MetS in later life (22-24). Therefore, weight gain during early infancy is a potential target for preventive intervention (25).

\section{SGA INFANTS WITH POSTNATAL CATCH-UP GROWTH DURING CHILDHOOD}

It is now generally accepted that children born SGA with catchup growth are at particularly high metabolic risk. Stevens et al. investigated the metabolic profiling of children born SGA that exhibited catch-up growth. Compared with noncatch-up SGA children, catch-up SGA children had greater BMI z-scores, insulin-like growth factor-I (IGF-I) levels, and fasting glucose levels, but lower adiponectin values at age 4-9 $y$, suggesting a greater risk of cardiometabolic diseases (26). In another study, Deng et al. investigated insulin resistance in term SGA children with catch-up growth, and found that the insulin resistance values of the homeostatic model assessment (HOMA-IR) were significantly higher in term catch-up SGA children than in term non-catch-up SGA and term appropriate for gestational age (AGA) children (27). These findings have been confirmed in animal models that employed prenatal nutrient restriction to produce LBW newborns, followed by catch-up growth (28-30). Furthermore, studies using animal models have revealed that postnatal catch-up growth induces subcutaneous (s.c.) fat remodeling (29) and alters the adipose tissue gene expression program, leading to obesity (30).

However, a follow-up study of term AGA infants has demonstrated that postnatal rapid growth (defined as an increase in the z-score for weight of $>0.67$ between birth and $24 \mathrm{mo}$ ) has a strong, significant, and independent effect on body fat percentage $(\% \mathrm{BF})$ at $2 \mathrm{y}$ of age, and this effect persisted and influenced $\mathrm{BMI}$ and \%BF trajectories between 2 and $7 \mathrm{y}$ of age (31). Several studies have also confirmed a similar phenomenon in normal birth weight infants that exhibit rapid weight gain $(6,32-34)$. Therefore, the association between postnatal catch-up growth during childhood and the risk of developing obesity is not specific to children born SGA. This growth pattern is similar to "adiposity rebound," which is accepted as a biomarker of adult obesity.

\section{POSTNATAL CATCH-UP FAT AND ALTERATION OF BODY COMPOSITION DURING EARLY INFANCY}

The importance of body composition rather than standard anthropometry alone has recently been emphasized regarding the assessment of postnatal rapid growth in preterm and SGA infants. Interestingly, changes in body composition and catchup fat begin quite early in the neonatal period.

\section{Preterm AGA vs. Term AGA Infants}

Several studies report on the body composition of preterm infants at term-equivalent age. In a meta-analysis of eight studies of infants with a mean gestational age of $30.0 \mathrm{wk}$, the body composition at term-equivalent age exhibited less lean tissue but more similar fat mass (and therefore higher \%BF) than infants born at term (34). Ramel et al. also investigated the body composition of preterm AGA infants born at $31.5 \mathrm{wk}$ of gestation and term AGA infants at term-equivalent age (35), and observed markedly lower fat-free mass and higher adiposity in preterm infants. In addition, Giannì et al. investigated changes in the body composition of late preterm AGA infants at gestational age $35.2 \mathrm{wk}$ in a cohort study from birth (36). Late preterm AGA infants at birth exhibited a significantly lower birth weight and \%BF (5.7\%); however, at term-equivalent age, they were heavier and exhibited a great increase in fat mass so that they had higher \%BF (16.1\%) than term AGA infants have at birth (8.9\%). These findings indicated that the late preterm AGA infants exhibited over-catch-up in both body weight and fat mass during early postnatal age. 


\section{Review $\mid$ Okada et al.}

\section{Term SGA vs. Term AGA Infants}

Like preterm infants, term SGA infants exhibited lower lean body mass, lower fat mass, and lower $\% \mathrm{BF}$ at birth than term AGA infants (37); they also exhibited early postnatal catch-up fat (38).

\section{Preterm SGA vs. Preterm AGA Infants}

Roggero et al. (39) investigated body composition in LBW infants $(<1500 \mathrm{~g})$, and found that LBW SGA infants born at 31.4 wk of gestation had lower \%BF than AGA infants born at $29.3 \mathrm{wk}$. In a cohort study of preterm infants, SGA infants exhibited rapid gain of fat mass, and no difference between SGA and AGA infants was detected in \%BF at a corrected age 3 mo; however, the weight $\mathrm{z}$-score of SGA infants was persistently lower than that of AGA infants.

\section{Fat Distribution of SGA Infants}

In addition, when Harrington et al. evaluated s.c. and intraabdominal fat distribution in growth-restricted newborn infants born at or near term (40), they found that growthrestricted infants had less adipose tissue mass and altered fat distribution. In contrast to the highly significant differences in s.c. fat tissue between AGA and growth-restricted infants, they detected no significant difference in intra-abdominal adipose tissue. This finding suggests that s.c. and intra-abdominal adipose tissue components may be under different regulatory control during early postnatal catch-up.

These findings in preterm and SGA infants have been confirmed using various methods of body composition analysis, including dual energy $\mathrm{x}$-ray absorptiometry, air-displacement plethysmography, and magnetic resonance imaging. Although the methods differ, the obtained results are similar among the described studies. Therefore, the findings indicate that preterm and SGA infants grow in different ways from term AGA infants during the early postnatal period, particularly regarding the growth of s.c. adipose tissue.

Previously, s.c. fat accumulation has been evaluated by skinfold measurement $(41,42)$, and SGA infants have thinner skinfolds than AGA infants. We also measured skinfolds in a cohort study of SGA and AGA infants, and investigated its rapid postnatal change. The sum of the thicknesses of four skinfolds (triceps, biceps, suprailiac, and subscapular) was thinner in SGA infants at birth, and caught up to the measurement in AGA infants in 1 mo (43). Our finding using skinfold measurement also confirmed the postnatal catch-up fat phenomenon in SGA infants.

\section{POSSIBLE MECHANISMS OF POSTNATAL RAPID FAT ACCUMULATION}

In normal weight infants, s.c. adipose tissue grows in parallel with the change in fat cell size during the first months of life; however, the number of fat cells remains stable $(44,45)$. In preterm and SGA infants, postnatal catch-up growth is accompanied by rapid and marked fat accumulation. This process is regulated by several endocrine and nutritional factors, as well as environmental factors such as cold stimulus (46).
Investigating the mechanism of postnatal rapid fat accumulation, a phenomenon specific to preterm and SGA infants, may provide insights regarding the long-term consequences that lead to MetS. Some recent studies involving rats with intrauterine growth restriction have demonstrated that rapid postnatal catch-up growth induces epigenetic modification of IGF-I and that postnatal leptin exposure modifies thrifty metabolic programming $(47,48)$.

\section{Lipoprotein Lipase (LPL)}

LPL is an important factor for lipid deposition in adipose tissue (49). An in vitro study of 3T3-L1 preadipocytes showed that LPL mRNA expression increased sixfold during differentiation; this change in expression resulted in a twofold increase in cell surface-associated LPL and a 10-fold increase in intracellular lipid storage (50). In an in vivo study with chickens, the administration of monoclonal antibodies against LPL in adipose tissue caused the inhibition of LPLmediated hydrolysis of very-low-density lipoprotein (VLDL) triglyceride (TG); consequently, the adipose fat weight was reduced (51). Although adipose tissue is able to synthesize free fatty acids de novo, free fatty acids for lipid storage are preferentially provided by LPL-mediated hydrolysis (52). In addition, studies using genetically engineered mouse models demonstrated that LPL activity is a major determinant of adipose tissue development (53).

We previously measured LPL mass (LPLm) levels in SGS and AGA infants at birth and 1 mo of age to investigate the influence of LPL on rapid s.c. fat accumulation (43). LPLm in nonheparinized serum is a useful, physiologically relevant index of LPL-mediated lipolysis of plasma TG $(54,55)$. We found that LPLm level had a positive relationship with skinfold thickness and an inverse relationship with VLDL-TG levels at birth and at $1 \mathrm{mo}$. This finding suggests that LPL-mediated TG uptake from VLDLs might be a major mechanism of s.c. fat accumulation in neonates. In addition, LPLm level increased markedly (+111.6\%; -14.8 to $577.8 \%)$ during $1 \mathrm{mo}$, and the change in LPLm level correlated positively with the change in skinfold thickness. Furthermore, the percent increase in serum LPLm level correlated inversely with the birth weight $\mathrm{z}$-score. Therefore, rapid postnatal increase in LPL-mediated TG uptake from VLDLs may be a major mechanism underlying the rapid postnatal s.c. fat accumulation exhibited in SGA infants.

\section{Insulin-Like Growth Factor-I (IGF-I)}

Insulin-like growth factors and corresponding binding proteins are important in the regulation of fetal and neonatal growth. Previous studies have shown that IGF-I has a more critical role than the other factors (56-58), and growth hormone is not an important regulator of IGF-I secretion during perinatal life $(57,58)$. In addition, children with IGF-I gene deletion are characterized by severe prenatal and postnatal growth retardation (59). Furthermore, IGF-I is centrally involved in adipocyte differentiation and adipose tissue development (60), as well as in linear growth. 


\section{Body composition of preterm SGA infants}

The impact of IGF-I on early postnatal growth has been investigated in many studies. In healthy term infants, growth velocity during the first week of life has a strong and positive association with IGF-I (56). In preterm infants, an association has also been demonstrated between IGF-I and early postnatal growth $(61,62)$. In a study of preterm infants (gestational age, $30.6 \mathrm{wk}$ ) (61), IGF-I was associated with weight $\mathrm{z}$-score at term and at a corrected age of $3 \mathrm{mo}$, and IGF-I at term age was negatively associated with a gain in weight $\mathrm{z}$-score between term age and a corrected age of $6 \mathrm{mo}$, independent of nutrient intake. Giapros et al. (62) investigated the relationship between IGF-I and postnatal growth in late preterm AGA infants (gestational age, 32-36wk) and found that IGF-I level was higher in infants that exhibited faster weight gain.

The effect of IGF-I level on rapid postnatal growth has also been investigated in SGA infants. Term SGA infants exhibited a positive correlation between birth weight and cord blood IGF-I, and those with slow growth during the first 15 postnatal days had lower cord blood IGF-I levels than newborns with normal growth (63). These findings suggest that IGF-I has some impact on the initiation of early postnatal rapid growth. In another study of term SGA infants, significantly lower IGF-I levels were documented in cord blood and at $1 \mathrm{~d}$ of age; however, this difference became statistically nonsignificant on postnatal day 4 (64). This indicates that metabolic catch-up of IGF-I is exhibited at a very early postnatal age, before catch-up growth begins.

We also measured IGF-I levels in the cohort study described above (43). The serum IGF-I level also correlated positively with body weight and the respective sums of skinfold thickness at birth and at $1 \mathrm{mo}$. In addition, changes in skinfold thickness during the first month correlated positively with the change in serum IGF-I level. Furthermore, the percent increase over 1 mo in both serum IGF-I level and LPLm level correlated inversely with the birth weight $\mathrm{z}$-score, suggesting that the marked postnatal increase of IGF-I observed in SGA infants is another mechanism of rapid postnatal s.c. fat accumulation.

\section{Adiponectin}

Adiponectin is an adipocytokine produced exclusively by adipocytes and has potential antidiabetic, antiatherosclerotic, and anti-inflammatory properties. Adiponectin is abundant in the cord blood of term neonates, at levels two- to threefold higher than those reported in adults. The relationship between cord blood adiponectin level and fetal growth has been investigated previously. Mantzoros et al. demonstrated that cord blood adiponectin in term infants is associated with gestational age at birth and birth weight/gestational age z-score (65). Tsai et al. also examined the relationship in healthy term infants, and found that adiponectin level correlated positively with birth weight and skinfold thickness (66). In addition, they observed a significant difference in adiponectin level between term SGA and term AGA infants, and serum adiponectin level correlated positively with birth weight (67). However, in offspring of diabetic mothers who were heavy at birth, cord blood adiponectin levels exhibited no significant relationship with birth weight z-score or skinfold thickness (68). These findings suggest that, contrary to what has been demonstrated in adults, cord blood adiponectin levels have a positive association with body fatness; thus, cord blood adiponectin levels are modulated differently from adult plasma.

In our previous cohort study of term infants (69), cord blood adiponectin levels were strongly related to birth weight and skinfold thickness; however, these relationships were not demonstrated in 1-mo-old infants. Adiponectin levels increased markedly during $1 \mathrm{mo}$ along with s.c. fat accumulation. However, the postnatal change in adiponectin level during the neonatal period does not correlate with weight gain or s.c. fat accumulation. In another cohort study reported by Bozzola et al. (70), adiponectin and adiponectin isoform distribution were measured at postnatal day 2 and at 1,6 , and 12 mo of age in SGA infants, when they exhibited catch-up growth. Total and isoform (high, medium, and low molecular weight) adiponectin levels were comparable between SGA and AGA infants at postnatal day 2 and until 12 mo of age. Taken together, these findings suggest that adiponectin has an effect on fetal growth, but no strong effect on early postnatal growth.

\section{Leptin}

Leptin, which is secreted from adipocytes, has important roles regarding energy expenditure and insulin sensitivity. Leptin is also present in cord blood, and its level correlates positively with gestational age, birth weight/birth weight $\mathrm{z}$-score, and skinfold thickness (65-67). However, an abrupt decrease in leptin level shortly after birth suggests that the placenta might be an important source of leptin in fetal circulation (71). After the early postnatal decrease of leptin, SGA infants persistently had lower leptin levels than AGA infants; however, relationships between leptin level and body fatness were not demonstrated (72).

In a cohort study of preterm infants at 7, 30, and $90 \mathrm{~d}$ of age, serum leptin levels were higher among term infants than among preterm infants at postnatal days 7 and 30; however, this difference was not significant at postnatal day 90 , and s.c. adipose tissue had a greater influence on leptin level than body weight at postnatal days 30 and 90 (73). In another study of preterm infants, the change in leptin was not associated with postnatal weight gain during $4 \mathrm{wk}$ (74). The impact of low leptin level at birth on postnatal rapid growth with marked fat accumulation in preterm and SGA infants remains to be elucidated in future studies.

\section{Other Factors}

Postnatal catch-up growth is regulated by nutritional factors and hormones. In studies that employ animal models, prenatal low protein and postnatal high fat and high calorie intake result in rapid catch-up growth of adipose tissue $(75,76)$. Therefore, the promotion of rapid weight gain in SGA infants using nutrient-enriched formula-feeding should be undertaken with caution. In a human study, breastfed SGA infants developed lower adiposity across early infancy (77). In addition, breastfed SGA infants maintained low fat mass and normal levels of IGF-I and 
high molecular weight adiponectin; formula-fed SGA infants normalized their body composition by gaining more fat, which was accompanied by a marked fall in high molecular weight adiponectin (78). Furthermore, lower levels of cord blood polyunsaturated fatty acids were associated with abdominal fat accumulation at $2 \mathrm{wk}$ of age (79). The role of human milk should be reevaluated from a new viewpoint (80).

\section{CONCLUSIONS}

Recent studies have shown that preterm and SGA infants exhibit unique postnatal growth with respect to weight gain composition. During the early postnatal period, they accumulate more fat than term AGA infants, especially in s.c. adipose tissue; therefore, they catch-up in fat earlier than they catch-up in body weight and height. In addition, some hormonal and metabolic factors (e.g., IGF-I and LPL) also exhibited early postnatal increases with fat accumulation. Furthermore, the metabolic catch-up of IGF-I appears to precede catch-up fat. In previous studies, the degree of "mismatch" between prenatal and postnatal environments was estimated simply by postnatal rapid weight gain. However, postnatal rapid fat accumulation and catch-up of metabolic factors might be more precise biomarkers to evaluate "mismatch."

The association of the catch-up fat phenomenon during early infancy with long-term metabolic consequences has not been investigated in humans, because the precise methods to assess infants' body composition have only been developed and applied quite recently. In addition, the mechanical contribution of hormonal and metabolic factors to fat accumulation during the early postnatal period has not been confirmed; previous studies demonstrated only associated changes in the serum levels of the factors. The precise mechanism of postnatal rapid fat accumulation should be investigated properly. Additional studies are necessary to evaluate the precise risks of postnatal rapid fat accumulation by examining the long-term consequences of altering metabolic markers. We hope that such studies will provide some suggestion of how best to establish nutritional options for preterm and SGA infants, and suggest possible mechanisms underlying developmental origins of health and disease.

\section{STATEMENT OF FINANCIAL SUPPORT}

No financial assistance was received to support this study.

Disclosure: The authors declare no conflict of interest.

\section{REFERENCES}

1. Weiss R, Dziura J, Burgert TS, et al. Obesity and the metabolic syndrome in children and adolescents. N Engl J Med 2004;350:2362-74.

2. Barker DJ, Osmond C. Infant mortality, childhood nutrition, and ischaemic heart disease in England and Wales. Lancet 1986;1:1077-81.

3. Barker DJ. The origins of the developmental origins theory. J Intern Med 2007;261:412-7.

4. Barker DJ. The developmental origins of chronic adult disease. Acta Paediatr Suppl 2004;93:26-33.

5. Barker DJ, Gluckman PD, Godfrey KM, Harding JE, Owens JA, Robinson JS. Fetal nutrition and cardiovascular disease in adult life. Lancet 1993;341:938-41.
6. Leunissen RW, Kerkhof GF, Stijnen T, Hokken-Koelega A. Timing and tempo of first-year rapid growth in relation to cardiovascular and metabolic risk profile in early adulthood. JAMA 2009;301:2234-42.

7. Godfrey KM, Lillycrop KA, Burdge GC, Gluckman PD, Hanson MA. Epigenetic mechanisms and the mismatch concept of the developmental origins of health and disease. Pediatr Res 2007;61:5 Pt 2:5R-10R.

8. Nobili V, Alisi A, Panera N, Agostoni C. Low birth weight and catch-upgrowth associated with metabolic syndrome: a ten year systematic review. Pediatr Endocrinol Rev 2008;6:241-7.

9. Boguszewski MC, Mericq V, Bergada I, et al. Latin American consensus: children born small for gestational age. BMC Pediatr 2011;11:66.

10. Clark PM. Programming of the hypothalamo-pituitary-adrenal axis and the fetal origins of adult disease hypothesis. Eur J Pediatr 1998;157:Suppl 1:S7-10.

11. van Montfoort N, Finken MJ, le Cessie S, Dekker FW, Wit JM. Could cortisol explain the association between birth weight and cardiovascular disease in later life? A meta-analysis. Eur J Endocrinol 2005;153:811-7.

12. Cianfarani S, Geremia C, Scott CD, Germani D. Growth, IGF system, and cortisol in children with intrauterine growth retardation: is catch-up growth affected by reprogramming of the hypothalamic-pituitary-adrenal axis? Pediatr Res 2002;51:94-9.

13. Bloomfield FH, Oliver MH, Hawkins P, et al. A periconceptional nutritional origin for noninfectious preterm birth. Science 2003;300:606.

14. Buhl ES, Neschen S, Yonemitsu S, et al. Increased hypothalamicpituitary-adrenal axis activity and hepatic insulin resistance in lowbirth-weight rats. Am J Physiol Endocrinol Metab 2007;293:E1451-8.

15. Gardner DS, Van Bon BW, Dandrea J, et al. Effect of periconceptional undernutrition and gender on hypothalamic-pituitary-adrenal axis function in young adult sheep. J Endocrinol 2006;190:203-12.

16. Chadio SE, Kotsampasi B, Papadomichelakis G, et al. Impact of maternal undernutrition on the hypothalamic-pituitary-adrenal axis responsiveness in sheep at different ages postnatal. J Endocrinol 2007;192:495-503.

17. Hattersley AT, Tooke JE. The fetal insulin hypothesis: an alternative explanation of the association of low birthweight with diabetes and vascular disease. Lancet 1999;353:1789-92.

18. Schlemm L, Haumann HM, Ziegner M, et al. New evidence for the fetal insulin hypothesis: fetal angiotensinogen $\mathrm{M} 235 \mathrm{~T}$ polymorphism is associated with birth weight and elevated fetal total glycated hemoglobin at birth. J Hypertens 2010;28:732-9.

19. Adkins RM, Somes G, Morrison JC, et al. Association of birth weight with polymorphisms in the IGF2, H19, and IGF2R genes. Pediatr Res 2010;68:429-34.

20. Freathy RM, Mook-Kanamori DO, Sovio U, et al. Variants in ADCY5 and near CCNL1 are associated with fetal growth and birth weight. Nat Genet 2010;42:430-5.

21. Eriksson JG, Forsén T, Tuomilehto J, Winter PD, Osmond C, Barker DJ. Catch-up growth in childhood and death from coronary heart disease: longitudinal study. BMJ 1999;318:427-31.

22. Ong KK, Loos RJ. Rapid infancy weight gain and subsequent obesity: systematic reviews and hopeful suggestions. Acta Paediatr 2006;95:904-8.

23. Nobili V, Alisi A, Panera N, Agostoni C. Low birth weight and catch-upgrowth associated with metabolic syndrome: a ten year systematic review. Pediatr Endocrinol Rev 2008;6:241-7.

24. Leunissen RW, Kerkhof GF, Stijnen T, Hokken-Koelega AC. Effect of birth size and catch-up growth on adult blood pressure and carotid intimamedia thickness. Horm Res Paediatr 2012;77:394-401.

25. Kerkhof GF, Hokken-Koelega AC. Rate of neonatal weight gain and effects on adult metabolic health. Nat Rev Endocrinol 2012;8:689-92.

26. Stevens A, Bonshek C, Whatmore A, et al. Insights into the pathophysiology of catch-up compared with non-catch-up growth in children born small for gestational age: an integrated analysis of metabolic and transcriptomic data. Pharmacogenomics J 2014;14:376-84.

27. Deng HZ, Li YH, Su Z, et al. Association between height and weight catchup growth with insulin resistance in pre-pubertal Chinese children born small for gestational age at two different ages. Eur J Pediatr 2011;170:75-80. 


\section{Body composition of preterm SGA infants | ReVieW}

28. Desai M, Babu J, Ross MG. Programmed metabolic syndrome: prenatal undernutrition and postweaning overnutrition. Am J Physiol Regul Integr Comp Physiol 2007;293:R2306-14.

29. Kohmura YK, Kanayama N, Muramatsu K, et al. Association between body weight at weaning and remodeling in the subcutaneous adipose tissue of obese adult mice with undernourishment in utero. Reprod Sci 2013;20:813-27.

30. Bol VV, Delattre AI, Reusens B, Raes M, Remacle C. Forced catch-up growth after fetal protein restriction alters the adipose tissue gene expression program leading to obesity in adult mice. Am J Physiol Regul Integr Comp Physiol 2009;297:R291-9.

31. Karaolis-Danckert N, Buyken AE, Bolzenius K, Perim de Faria C, Lentze MJ, Kroke A. Rapid growth among term children whose birth weight was appropriate for gestational age has a longer lasting effect on body fat percentage than on body mass index. Am J Clin Nutr 2006;84:1449-55.

32. Ong KK, Ahmed ML, Emmett PM, Preece MA, Dunger DB. Association between postnatal catch-up growth and obesity in childhood: prospective cohort study. BMJ 2000;320:967-71.

33. Monteiro PO, Victora CG. Rapid growth in infancy and childhood and obesity in later life—a systematic review. Obes Rev 2005;6:143-54.

34. Johnson MJ, Wootton SA, Leaf AA, Jackson AA. Preterm birth and body composition at term equivalent age: a systematic review and meta-analysis. Pediatrics 2012;130:e640-9.

35. Ramel SE, Gray HL, Ode KL, Younge N, Georgieff MK, Demerath EW. Body composition changes in preterm infants following hospital discharge: comparison with term infants. J Pediatr Gastroenterol Nutr 2011;53:333-8.

36. Giannì ML, Roggero P, Liotto N, et al. Postnatal catch-up fat after late preterm birth. Pediatr Res 2012;72:637-40.

37. Verkauskiene R, Beltrand J, Claris O, et al. Impact of fetal growth restriction on body composition and hormonal status at birth in infants of small and appropriate weight for gestational age. Eur J Endocrinol 2007;157: 605-12.

38. Modi N, Thomas EL, Harrington TA, Uthaya S, Doré CJ, Bell JD. Determinants of adiposity during preweaning postnatal growth in appropriately grown and growth-restricted term infants. Pediatr Res 2006;60: 345-8.

39. Roggero P, Giannì ML, Liotto N, et al. Rapid recovery of fat mass in small for gestational age preterm infants after term. PLoS One 2011;6:e14489.

40. Harrington TA, Thomas EL, Frost G, Modi N, Bell JD. Distribution of adipose tissue in the newborn. Pediatr Res 2004;55:437-41.

41. Excler JL, Sann L, Lasne Y, Picard J. Anthropometric assessment of nutritional status in newborn infants. Discriminative value of mid arm circumference and of skinfold thickness. Early Hum Dev 1985;11:169-78.

42. Yau KI, Chang MH. Growth and body composition of preterm, small-forgestational-age infants at a postmenstrual age of 37-40 weeks. Early Hum Dev 1993;33:117-31.

43. Yoshikawa K, Okada T, Munakata S, et al. Association between serum lipoprotein lipase mass concentration and subcutaneous fat accumulation during neonatal period. Eur J Clin Nutr 2010;64:447-53.

44. Häger A, Sjöstrm L, Arvidsson B, Björntorp P, Smith U. Body fat and adipose tissue cellularity in infants: a longitudinal study. Metabolism 1977;26:607-14.

45. Soriguer Escofet FJ, Esteva de Antonio I, Tinahones FJ, Pareja A. Adipose tissue fatty acids and size and number of fat cells from birth to 9 years of age-a cross-sectional study in 96 boys. Metabolism 1996;45:1395-401.

46. Symonds ME, Mostyn A, Pearce S, Budge H, Stephenson T. Endocrine and nutritional regulation of fetal adipose tissue development. J Endocrinol 2003;179:293-9.

47. Tosh DN, Fu Q, Callaway CW, et al. Epigenetics of programmed obesity: alteration in IUGR rat hepatic IGF1 mRNA expression and histone structure in rapid vs. delayed postnatal catch-up growth. Am J Physiol Gastrointest Liver Physiol 2010;299:G1023-9.

48. Ellis PJ, Morris TJ, Skinner BM, et al. Thrifty metabolic programming in rats is induced by both maternal undernutrition and postnatal leptin treatment, but masked in the presence of both: implications for models of developmental programming. BMC Genomics 2014;15:49.
49. Zechner R, Strauss J, Frank S, et al. The role of lipoprotein lipase in adipose tissue development and metabolism. Int J Obes Relat Metab Disord 2000;24:Suppl 4:S53-6.

50. Gonzales AM, Orlando RA. Role of adipocyte-derived lipoprotein lipase in adipocyte hypertrophy. Nutr Metab (Lond) 2007;4:22.

51. Sato K, Akiba Y, Chida Y, Takahashi K. Lipoprotein hydrolysis and fat accumulation in chicken adipose tissues are reduced by chronic administration of lipoprotein lipase monoclonal antibodies. Poult Sci 1999;78:1286-91.

52. Hollenberg $\mathrm{CH}$. The origin and glyceride distribution of fatty acids in rat adipose tissue. J Clin Invest 1966;45:205-16.

53. Voshol PJ, Rensen PC, van Dijk KW, Romijn JA, Havekes LM. Effect of plasma triglyceride metabolism on lipid storage in adipose tissue: studies using genetically engineered mouse models. Biochim Biophys Acta 2009;1791:479-85.

54. Kern PA, Martin RA, Carty J, Goldberg IJ, Ong JM. Identification of lipoprotein lipase immunoreactive protein in pre- and postheparin plasma from normal subjects and patients with type I hyperlipoproteinemia. J Lipid Res 1990;31:17-26.

55. Kobayashi J, Hashimoto H, Fukamachi I, et al. Lipoprotein lipase mass and activity in severe hypertriglyceridemia. Clin Chim Acta 1993;216:113-23.

56. Klauwer D, Blum WF, Hanitsch S, Rascher W, Lee PD, Kiess W. IGF-I, IGFII, free IGF-I and IGFBP-1, -2 and - 3 levels in venous cord blood: relationship to birthweight, length and gestational age in healthy newborns. Acta Paediatr 1997;86:826-33.

57. Wollmann HA. Growth hormone and growth factors during perinatal life. Horm Res 2000;53:Suppl 1:50-4.

58. Skalkidou A, Petridou E, Papathoma E, Salvanos H, Trichopoulos D. Growth velocity during the first postnatal week of life is linked to a spurt of IGF-I effect. Paediatr Perinat Epidemiol 2003;17:281-6.

59. Woods KA, Camacho-Hübner C, Savage MO, Clark AJ. Intrauterine growth retardation and postnatal growth failure associated with deletion of the insulin-like growth factor I gene. N Engl J Med 1996;335:1363-7.

60. Blüher S, Kratzsch J, Kiess W. Insulin-like growth factor I, growth hormone and insulin in white adipose tissue. Best Pract Res Clin Endocrinol Metab 2005;19:577-87.

61. van de Lagemaat M, Rotteveel J, Heijboer AC, Lafeber HN, van Weissenbruch MM. Growth in preterm infants until six months postterm: the role of insulin and IGF-I. Horm Res Paediatr 2013;80:92-9.

62. Giapros VI, Schiza V, Challa AS, Pantou C, Theocharis PD, Andronikou SK. Serum insulin-like growth factor I (IGF-I), IGF-binding proteins- 1 and -3 , and postnatal growth of late preterm infants. Horm Metab Res 2012;44:845-50.

63. Orbak Z, Darcan S, Coker M, Gökşen D. Maternal and fetal serum insulinlike growth factor-I (IGF-I) IGF binding protein-3 (IGFBP-3), leptin levels and early postnatal growth in infants born asymmetrically small for gestational age. J Pediatr Endocrinol Metab 2001;14:1119-27.

64. Malamitsi-Puchner A, Briana DD, Gourgiotis D, et al. Insulin-like growth factor (IGF)-I and insulin in normal and growth-restricted mother/infant pairs. Mediators Inflamm 2007;2007:42646.

65. Mantzoros CS, Rifas-Shiman SL, Williams CJ, Fargnoli JL, Kelesidis T, Gillman MW. Cord blood leptin and adiponectin as predictors of adiposity in children at 3 years of age: a prospective cohort study. Pediatrics 2009;123:682-9.

66. Tsai PJ, Yu CH, Hsu SP, et al. Cord plasma concentrations of adiponectin and leptin in healthy term neonates: positive correlation with birthweight and neonatal adiposity. Clin Endocrinol (Oxf) 2004;61:88-93.

67. Kamoda T, Saitoh H, Saito M, Sugiura M, Matsui A. Serum adiponectin concentrations in newborn infants in early postnatal life. Pediatr Res 2004;56:690-3.

68. Lindsay RS, Walker JD, Havel PJ, Hamilton BA, Calder AA, Johnstone FD; Scottish Multicentre Study of Diabetes Pregnancy. Adiponectin is present in cord blood but is unrelated to birth weight. Diabetes Care 2003;26: 2244-9.

69. Inami I, Okada T, Fujita H, et al. Impact of serum adiponectin concentration on birth size and early postnatal growth. Pediatr Res 2007;61:5 Pt 1:604-6. 
70. Bozzola E, Meazza C, Arvigo M, et al. Role of adiponectin and leptin on body development in infants during the first year of life. Ital J Pediatr 2010;36:26.

71. Valūniene M, Verkauskiene R, Boguszewski M, et al. Leptin levels at birth and in early postnatal life in small- and appropriate-for-gestational-age infants. Medicina (Kaunas) 2007;43:784-91.

72. Orbak Z, Coker M, Darcan S, Gökşen D. Association between serum leptin and anthropometric parameters at birth and at 15th day of life in infants born asymmetrically small for gestational age. J Pediatr Endocrinol Metab 2001;14:185-92.

73. Toprak D, Gökalp AS, Hatun S, Zengin E, Arisoy AE, Yumuk Z. Serum leptin levels of premature and full-term newborns in early infancy: metabolic catch-up of premature babies. Turk J Pediatr 2004;46:232-8.

74. Lo HC, Tsao LY, Hsu WY, Chi CY, Tsai FA. Changes in serum insulin-like growth factors, not leptin, are associated with postnatal weight gain in preterm neonates. JPEN J Parenter Enteral Nutr 2005;29:87-92.

75. Claycombe KJ, Uthus EO, Roemmich JN, Johnson LK, Johnson WT. Prenatal low-protein and postnatal high-fat diets induce rapid adipose tissue growth by inducing Igf2 expression in Sprague Dawley rat offspring. J Nutr 2013;143:1533-9.

76. Bol VV, Delattre AI, Reusens B, Raes M, Remacle C. Forced catch-up growth after fetal protein restriction alters the adipose tissue gene expression program leading to obesity in adult mice. Am J Physiol Regul Integr Comp Physiol 2009;297:R291-9.

77. Ibáñez L, Sebastiani G, Diaz M, Gómez-Roig MD, Lopez-Bermejo A, de Zegher F. Low body adiposity and high leptinemia in breast-fed infants born small-for-gestational-age. J Pediatr 2010;156:145-7.

78. de Zegher F, Sebastiani G, Diaz M, Sánchez-Infantes D, Lopez-Bermejo A, Ibáñez L. Body composition and circulating high-molecular-weight adiponectin and IGF-I in infants born small for gestational age: breast- versus formula-feeding. Diabetes 2012;61:1969-73.

79. Sanz N, Diaz M, López-Bermejo A, et al. Newborns with lower levels of circulating polyunsaturated fatty acids (PUFA) are abdominally more adipose. Pediatr Obes 2014;9:e68-72.

80. Agostoni C. Small-for-gestational-age infants need dietary quality more than quantity for their development: the role of human milk. Acta Paediatr 2005;94:827-9. 